\section{Supporting your air}

\section{compressor}

Are you worried about your air compressor failing to function or becoming non-compliant?

Why not let DentalAir wave away your worries by joining their Aircare Adoption Programme? A unique service that offers complete care and maintenance for your existing air compressor, DentalAir is happy to extend this service to all makes of existing compressors!

The DentalAir pledge includes:

$\rightarrow$ Total Air Care

$\rightarrow$ Peace of mind

$\rightarrow$ Reliability and confidence

$\rightarrow$ 24-hour back-up support

$\rightarrow$ Swift national service

$\rightarrow$ Air qualities tested (AIR QUALITY

TEST, as required by $\mathrm{CQC}$ ).

All from as little as $£ 9.50$ a week. For more information, contact DentalAir at info@dentalair.com or call 08009757530.

\section{Looking for your next move?}

When the time comes to take the next step and sell your dental practice, consider joining Rodericks Dental.

We are proud to do things differently. Our clinically-led ethos is reflected in everything that we do, as we prioritise quality patient care and the development of our professionals.

We understand what patients need and we understand how to support dentists in delivering on patient expectations. We live and breathe what our professional teams do and we aim to keep them safe from any unnecessary complaints or complications.

So, if you want to leave your practice, your team and your patients in safe hands, visit www.sellyourdentalpractice.net or contact Rebecca Bird at acquisitions@ rodericksdental.co.uk or on 01604602491 (option 5).

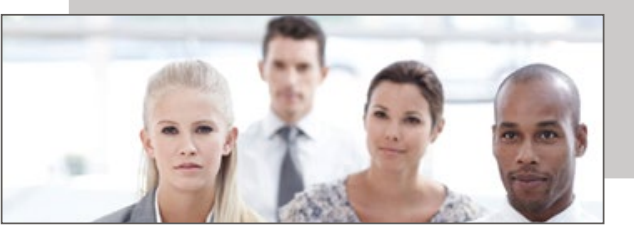

\title{
One cement three steps
}

Do you wish you had one cement to cover all clinical indications? Have you tried Panavia V5, distributed by J\&S Davis?

Requiring a simple application sequence with just three steps, Panavia V5 helps to streamline cementing procedures. Clinicians need only 1) prime and roughen the prosthetic, 2) prime the tooth and 3) apply the cement. That's it. A similar workflow can be utilised by lab technicians when cementing implant abutments as well.

Available in five shades and featuring an automix syringe for ultimate ease of use, Panavia V5 is the solution you're looking for.

For more information on the industryleading products available from J\&S Davis, visit www.js-davis.co.uk, call 01438747344 or email jsdsales@js-davis.co.uk.

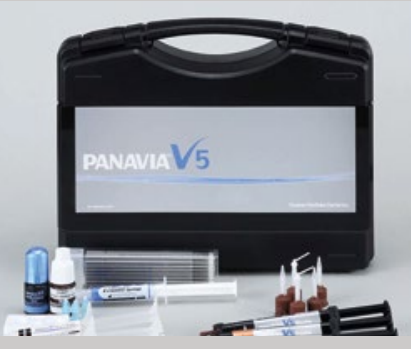

\section{Reduce the risks}

The CALCIVIS imaging system enables dental professionals to accurately monitor the tooth surfaces for activity over time. The screening procedure is completely painless and it can be used with patients from the age of six.

Using a bioluminescent photoprotein, the CALCIVIS imaging system detects free calcium ions as they are released from actively demineralising tooth enamel. It then

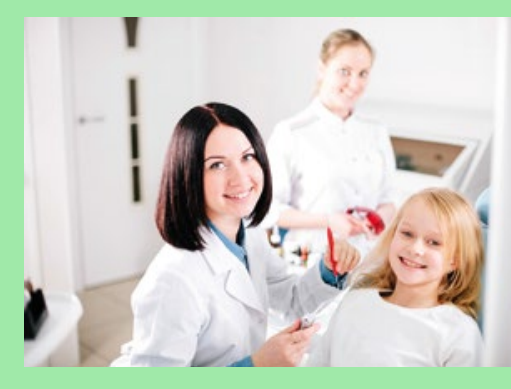
captures this information and generates definitive visual evidence of dental erosion and caries at the very early stages.

This enables preventive, non-invasive measures to be implemented immediately to reduce the risk of further disease progression.

For more details visit www.calcivis.com, call 01316585152 or email info@calcivis.com.

\section{Optimised intraoral imaging}

Offering industry-leading image resolution, the XIOS XG Supreme intraoral sensor supplied by Clark Dental is optimised for accurate diagnostics.

Featuring CMOS-APS (Active Pixel Sensor) technology, the XIOS XG Supreme is supported by intelligent software with task specific image enhancement functions These enable you to individually set image sharpness, brightness and contrast for five different diagnoses.

With its optional WiFi module, the XIOS XG Supreme offers the flexibility for you to use the sensor in multiple treatment rooms. The sensor's exchangeable cable also ensures you can alter the cable length as required or replace a damaged cable within minutes.
For more information, call Clark Dental on 01268733 146, email info@clarkdental. co.uk or visit www.clarkdental.co.uk.

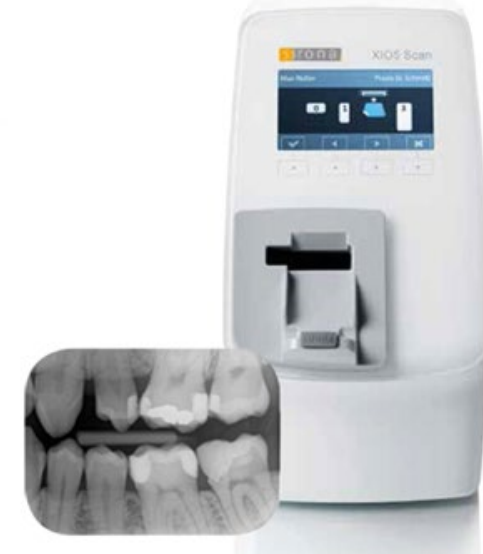

